\title{
REVIEW
}

\section{Adrenal metastases}

\author{
Wagnerova H, Lazurova I, Felsoci M \\ 1st Department of Internal Medicine, Medical Faculty PJ Safarikiensis University, Kosice, Slovakia. \\ ivica.lazurova@upjs.sk
}

\begin{abstract}
The adrenal gland is a frequent location for metastatic spread of a various number of malignant tumors. Among all tumors, carcinoma of lung, breast, ovary and malignant melanoma count to the most frequent ones. In nononcological and unselected populations, the prevalence of adrenal metastases is $0-21 \%$. The metastases are mostly discovered in patients during their follow-up carried out in consequence of their antecedent malignant disease. A malignant disease in adrenal gland may occasionally manifest as a solitary metastasis referred to as adrenal incidentaloma. If the malignant disease is disseminated at the time of adrenal mass diagnosis, no further differentiation of lesion is necessary as it does not influence the further therapeutic process. If the dissemination is not present, further differentiation of adrenal lesion is essential. CT and MRI characteristics of the adrenal mass play the key role in the differential diagnosis. The examination of adrenal overproduction is not necessary in case of known adrenal metastasis except when performing tests in order to rule out the catecholamine overproduction. In case of bilateral metastases, adrenal insufficiency should be also excluded. Surgical treatment is indicated in cases of solitary metastasis. The further management of patients with adrenal metastases belongs to the oncologist. The prognosis of the disease is usually very poor with average survival rate of three months (Fig. 2, Ref. 34). Full Text in PDF www.elis.sk.

Key words: adrenal metastases, imaging of adrenal tumors, adrenal incidentalomas, pheochromocytoma.
\end{abstract}

The adrenal gland is a frequent location for metastatic spread of a various number of malignant tumors. Theoretically, every primary malignancy may disseminate into adrenal glands. Among all tumors, carcinoma of lung, breast, ovary and malignant melanoma count to the most frequent ones. Stomach cancer represents a less common cause of adrenal metastases while the potential of oncocytoma to spread into adrenal glands has been described as rare (1). Malignant lymphoma is being described as relatively frequent cause of bilateral adrenal infiltration.

\section{Epidemiology}

In nononcological and unselected populations, the prevalence of adrenal metastases is $0-21 \%$. In oncological patients, the prevalence is referred to be higher, namely in range of 32-73\% (2). Lenert et al report similar rates based on their finding that $52 \%$ of adrenal masses in 91patients with a recently diagnosed extraadrenal malignancy were metastatic (3). Meta-analysis of Cawood et al has shown that the estimated real prevalence is approximately $2.3 \%$ while higher occurrence is usually overestimated and originates from differently selected groups (4).

Autopsy studies in patients with malignant tumors of epithelial character have documented the prevalence of metastases to be even $27 \%(5,6)$. The occurrence rates of adrenal metastases

1st Department of Internal Medicine, Medical Faculty PJ Safarikiensis University, Kosice, Slovakia

Address for correspondence: I. Lazurova, MD, PhD, 1st Department of Internal Medicine, Medical Faculty PJ Safarikiensis University, Trieda SNP 1, SK-040 11 Kosice, Slovakia. in patients with breast carcinoma and lung carcinoma are $39 \%$ and $35 \%$, respectively $(5,6,7)$. Adrenal involvement is found in $46.8-50 \%$ of cases with malignant melanoma $(8,9)$. The adrenal gland is the second most common site of metastases from hepatocellular carcinoma (10). Lymphoma occasionally involves the adrenal gland with non Hodgkin's lymphoma which is more common than Hodgkin's disease at this site. In a retrospective study by Paling and Williamson, $4 \%$ of patients with non Hodgkin's lymphoma showed evidence of adrenal metastases (11). In cases of renal cell carcinoma, the metastases in the counter-lateral adrenal gland are extremely rare (12).

The metastases are mostly discovered in patients during their follow-up carried out in consequence of their antecedent malignant disease. An occasionally, malignant disease may manifest in form of solitary metastasis in the adrenal gland in form of adrenal incidentaloma.

Metastatic affliction may be either unilateral or bilateral. Bilateral involvement is seen in $50 \%$ of patients with lymphoma. Although bilateral metastases are more common than unilateral, in most cases they do not lead to adrenal insufficiency. The size of these secondary tumors may vary from small to huge (above $10 \mathrm{~cm})(13)$.

\section{Diagnosis}

The median duration from the diagnosis of primary cancer up to the identification of adrenal metastases is approximately 2.5 years. Sagalowsky et al described a case of a solitary metastasis to the counter-lateral adrenal gland 22 years after radical nephrectomy for renal cell carcinoma (14). 


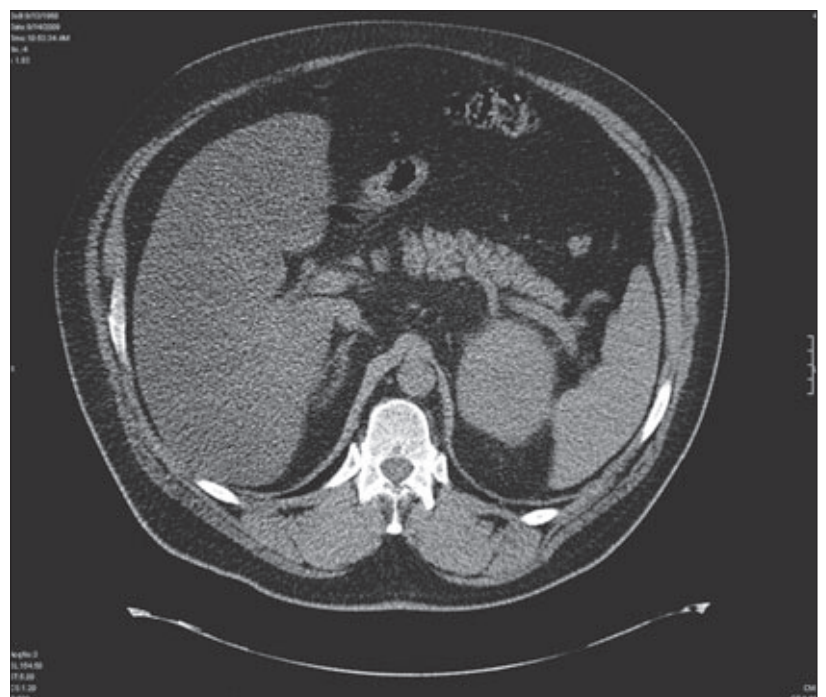

Fig. 1. CT view of metastasis of malignant melanoma into left adrenal gland. Normal CT view of right adrenal gland.

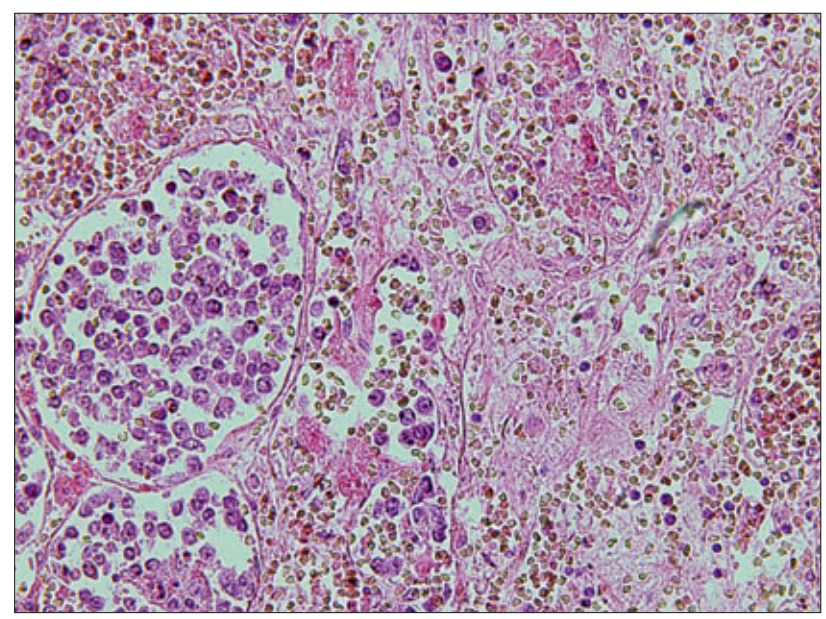

Fig. 2. Histological view of adrenal cortex with haemorrhage and collection of lymphoma cells in dilated capillaries. Hematoxylin-eosin staining, 200x (31).

In order to identify antecedent or present malignancy, particular history should be taken on every patient who by means of imaging methods is found to have adrenal incidentaloma. We inquire for weight loss, fever of unknown origin and smoking. In addition to latter inquiries, we should not forget to examine the family history of malignancies.

By physical examination, we look for the presence of lymphadenopathy, skin lesions of melanoma character, resistance in breast etc.

If by means of computed tomography (CT) or magnetic resonance, a lesion of adrenal gland is found in a patient with a known malignant disease and multiple organ dissemination, usually no further examination is necessary as it does not influence the further therapeutic process $(6,15)$. If oncological treatment was successfully completed and remission was induced with no signs of dissemination of the disease, further differentiation of the adrenal lesion is essential. CT and MRI with the evaluation of lesion's characteristics play the key role in differential diagnosis.

Benign adrenal masses contain abundant intracytoplasmic fat in contrast to lipid-poor malignant lesions. On unenhanced CT scan, attenuation value of $<10$ Hounsfield units (HU) suggests a lipid-containing benign adenoma with a specificity of more than $95 \%$ and sensitivity of $71 \%$. Approximately $29 \%$ of adenomas show an attenuation value of more than $10 \mathrm{HU}$ (lipid-poor adenomas) resulting in an indeterminate finding (16). Standard contrastenhanced CT images are obtained 60 seconds after contrast media administration. At this time the attenuation values of adenomas and metastases are nearly identical. Adenomas lose enhancement more rapidly. Masses with attenuation value of less than 30-40 HU on a contrast-enhanced CT scan obtained with a 15-minute delay are almost always adenomas. Another useful method available for differentiation between benign and malignant lesions is the calculation of the percentage of washout at 15 minutes after contrast media administration from the initial enhancement. Optimal threshold washout for adenoma is $60 \%$ with sensitivity and specificity of $86 \%$ and $92 \%$, respectively (17). Small metastases are usually homogeneous analogues of adenomas, whereas big metastases are often heterogeneous in appearance as a result of hemorrhages and necroses within the lesions. Calcifications are rare in metastases.

The intensity of signal of metastasis in T2 weighting of MRI is higher than that of benign and hormonally inactive lesions. According to several authors, faster washout of gadolinium in MRI is typical for adenomas and may distinguish them from metastatic lesions. However, other studies did not prove this relation and therefore dynamic-gadolinium MRI is not a standard method used for that purpose. The more recommended chemical-shift MRI potentially enabling to distinguish adenomas from metastases is based on a principle of difference in resonance of protons in lipids and water. The reported sensitivity and specificity results for a benign lesion were $87-100 \%$ and $92-100 \%$, respectively $(18,19)$. The rate of diagnostic failure could be high $(13-17 \%)$ in lipid-poor adenomas. Park et al 2007 compared delayed enhanced CT and chemical shift MRI for evaluating the hyperattenuating incidental adrenal masses $(>10 \mathrm{HU})$ on non-enhanced CT. Although there was no significant difference between the two imaging modalities, the delayed enhanced CT scans had higher sensitivity and specificity for lipid-poor adenoma than did the chemical-shift MR (10).

Recent studies documented the use of the contrast-enhanced doppler sonography on characterization of adrenal masses (20, 21). Friedrich-Rust et al. found an early arterial contrast enhancement and rapid washout in all patients with primary and secondary malignant lesions of adrenal gland and in only $22 \%$ of patients with benign adrenal masses at contrast-enhanced sonography. In the diagnosis of malignant adrenal mass, the sensitivity and specificity of contrast-enhanced sonography were $100 \%$ and 82 $\%$, respectively $(21)$.

${ }^{131}$ I-19-Iodocholesterol scintigraphy may be helpful in differentiating the metastases with typical absence of radiumcholesterol absorbtion in adrenal mass. 
${ }^{18} \mathrm{~F}$ FDG - PET is another method of distinguishing metastases from benign adrenal lesions. Yun et al 2001 found a sensitivity of $93 \%$ and specificity of $94 \%$ when using lesion uptake higher or equal to liver uptake as a criterion for the positive result (22). The most common type of tumor to cause false positive results on FDG-PET scan is reported to be that of pheochromocytoma of the adrenal (22). Lower FDG uptake has been reported in metastases from neuroendocrine tumors (23). Jana et al founded false negative lesions on FDG-PET in patients with pulmonary carcinoid (24). On the other hand, while the inhibitor of 11 beta-hydroxylase ${ }^{11} \mathrm{C}$ metomidat may distinguish adrenocortical carcinoma from metastases of tumors of noncortical origin, it is unable to differentiate between adrenal adenoma and adrenal carcinoma $(25,26)$.

The laboratory examination is not indicated in case of known malignancy and unilateral adrenal metastasis, however particularly in order to exclude the primary hypocortisolism, the hormonal evaluation of adrenal gland is obligatory in patients with bilateral masses of metastatic origin. In this case, the examination of serum cortisol, urinary free cortisol and serum ACTH is recommended, eventually including the ACTH test. The examination of adrenal overproduction is not necessary in case of known adrenal metastasis except for the evaluation which rules out catecholamine overproduction. Adler et al. found a surprisingly high incidence of pheochromocytomas in cancer patients. In their study of 33 patients with history of cancer who underwent resection of an adrenal lesion, nearly 1 of 4 patients had a pheochromocytoma rather than a metastasis or adenoma. Hypertension was the initial presenting symptom in $75 \%$ of patients with pheochromocytoma, however $25 \%$ of patients had neither hypertension nor any other classic symptoms of pheochromocytoma present (27). None of the clinical and radiographic parameters effectively ruled out the pheochromocytoma. Most pheochromocytomas demonstrate high-signal intensity on T2-weighted images on MRI. High signal intensity should not be used as a feature to suggest or exclude pheochromocytoma because these tumors manifest also with moderate signal intensity on T2-weighted images (28). The consequences of misdiagnosing a pheochromocytoma are grave. Screening for catecholamine overproduction should include the measurement of plasma metanephrines or 24-hour urinary metanephrines, the sensitivity of which is reported to be in range of 97-100\% (29). Tumor markers may be helpful when previous history of malignancy or malignant signs of adrenal tumor are present (25).

Adrenal biopsy is a nowadays method of relatively narrow indications and is performed mainly if the suspicion of malignant infiltration of adrenal gland by known primary oncological disease is present. Cytologic evidence of adrenal tissue excludes metastatic adrenal malignancy. Adrenal biopsy showing malignancy has a positive predictive value of $100 \%$ and a negative predictive value for malignancy of $92 \%$ (30). In case of bilateral masses, it may be valuable for identification of tuberculosis and other granulomatous lesions as well as of malignant lymphoma (Figs 1 and 2) (31). If the definitive diagnosis of adrenal malignancy is essential for oncological treatment, it may be performed under CT or ultrasound control. However, because of the risk of severe complications, the possibility of pheochromocytoma should be excluded first. Implantation metastases of carcinoma after percutaneous fine-needle aspiration biopsy were reported (32).

\section{Therapy and prognosis}

As written above, if the malignant disease is disseminated at the time of diagnosis of the adrenal mass, no further differentiation of lesion is necessary. If the dissemination is not present, further differentiation using imaging techniques should be performed. In case of bilateral metastases, adrenal insufficiency should be excluded in every patient. Surgical treatment is indicated in case of solitary metastases, where it may be included also in more radical procedures in order to minimize the tumor mass, i.e. debulking. Various case series documented the efficacy of transarterial chemoembolization and imaging-guided percutaneous radiofrequency ablation in local control of adrenal metastases $(33,34)$. The further management of patients with adrenal metastases belongs to the oncologist. The prognosis of the disease is usually very poor with average survival rate of 3 months.

\section{References}

1. Peppa M, Karamitopoulou E, Nikopoulos P et al. Large Adrenal Oncocytoma with uncertain malignant potential. A case report and review of the literature. Endocr Pract 2010; 16 (4): 641-645.

2. Kloos RT, Gross MD, Francis IR, Korobkin M, Shapiro B. Incidentally discovered adrenal masses. Endocr Rev 1995; 16 (4): 460-484.

3. Lenert JT, Barnett CC Jr, Kudelka AP et al. Evaluation and surgical resection of adrenal masses in patients with a history of extraadrenal malignancy. Surgery 2001; 130 (6): 1060-1067.

4. Cawood TJ, Hunt PJ, O'Shea D, Cole D, Soule S. Recommended evaluation of adrenal incidentalomas is costly, has high false positive rates and confers a risk of fatal cancer that is similar to the risk of the adrenal lesion becoming malignant: time for a rethink? Eur J Endocrinol 2009; 161 (4): 513-527.

5. Abrams HL, Spiro R, Goldstein N. Metastases in carcinoma: analysis of 1000 autopsied cases. Cancer 1950; 3 (1): 74-85.

6. Dunnick NR, Korobkin M. Imaging of adrenal incidentalomas: current status. Am J Roentgenol 2002; 179 (3): 559-569.

7. Zornoza J, Bracken R, Wallace S. Radiologic features of adrenal metastases. Urology 1976; 8 (3): 295-299.

8. Dasgupta T, Brasfield R. Metastatic melanoma. A clinicopathological study. Cancer 1964; 17: 1323-1339.

9. Patel JK, Didolkar MS, Pickren JW, Moore RH. Metastatic pattern of malignant melanoma. A study of 216 autopsy cases. Am J Surg 1978; 135 (6): 807-810.

10. Park JS, Yoon DS, Kim KS et al. What is the best treatment modality for adrenal metastasis from hepatocellular carcinoma? J Surg Oncol 2007; 96 (1): 32-36.

11. Paling MR, Williamson BR. Adrenal involvement in non-Hodgkin lymphoma. Am J Roentgenol 1983; 141 (2): 303-305.

12. Moudouni SM, En-Nia I, Rioux-Leclercq N, Guille F, Lobel B. Solitary contralateral adrenal metastasis after nephrectomy for renal cell carcinoma. Urol Int 2002; 68 (4): 295-298. 
$237-240$

13. Iacconi P, Donatini G, Iacconi C et al. Unexpected histological findings of lesions diagnosed in the adrenal region in a series of 420 patients submitted to adrenal surgery. Review of our experience. J Endocrinol Invest 2008; 31 (10): 873-876

14. Sagalowski AI, Molberg K. Solitary metastasis of renal cell carcinoma to the contralateral adrenal gland 22 years after nephrectomy. Urology 1994; 54 (1): 162.

15. Zeigher MA, Thompson GB, Duh QY, Hamrahian AH, Angelo $P$ et al. American Association of clinical endocrinologists and American Association of Endocrine Surgeons. Medical Guidelines for The Management of Adrenal Incidentalomas. Endocr Pract 2009; 15 (5), Suppl 1: 1-20.

16. Boland GW, Lee MJ, Gazelle GS, Halpern EF, McNicholas MM, Mueller PR. Characterization of adrenal masses using unenhanced CT: an analysis of the CT literature. Am J Roentgenol 1998; 171 (1): 201-204.

17. Caoili EM, Korobkin M, Francis IR et al. Adrenal masses: characterization with combined unenhanced and delayed enhanced CT. Radiology 2002; 222 (3): 629-633.

18. Outwater EK, Siegelman ES, Huang AB, Birnbaum BA. Adrenal masses: correlation between $\mathrm{CT}$ attenuation value and chemical shift ratio MR imaging with in-phase and opposed- phase sequences. Radiology 1996; 200 (2): 749-752.

19. Korobkin M, Lombardi TJ, Aisen AM et al. Characterization of adrenal masses with chemical shift and gadolinium - enhanced MR imaging. Radiology 1995; 197 (2): 411-418.

20. Slonina J, Nienartowicz E, Agrawal AK, Malczewska J, Moron K. The usefulness of contrast enhanced sonography in the differential diagnostic of adrenal tumors. Endokrynol Pol 2006; 57 (3): 230-236.

21. Friedrich-Rust M, Schneider G, Bohle MR et al. Contrast-enhanced sonography of adrenal masses: Differentiation of adenomas and nonadenomatous lesions. Am J Roentgenol 2008; 191 (6):1852-1860.

22. Yun M, Kim W, Alnafisi N, Lacorte L, Jang S, Alavi A. ${ }^{18}$ F- FDG PET in characterizing adrenal lesions detected on CT or MRI. J Nucl Med 2001; 42 (12): 1795-1799.

23. Erasmus JJ, McAdams HP, Patz EF Jr, Coleman RE, Ahuja V, Goodman PC. Evaluation of primary pulmonary carcinoid tumors using FDG PET. Am J Roentgenol 1998; 170 (5): 1369-1373.
24. Jana S, Zhang T, Milstein DM, Isasi CR, Blaufox MD. FDG-PET and CT characterization of adrenal lesions in cancer patients. Eur J Nucl Med Mol Imag 2006; 33 (1): 29-35.

25. Mansmann G, Lau J, Balk E, Rothberg M, Miyachi Y et al. The Clinically Inapparent Adrenal Mass: Update in Diagnosis and Management. Endocrine rewievs 2004; 25 (2): 309-340.

26. Gross MD, Korobkin M, Hussain HK, Cho KJ, Bui CH. Adrenal Gland Imaging. 2425-2453. In: De Groot LJ and Jameson JL (Eds). Endocrinology. Philadelphia; W.B. Saunders Comp, 2006.

27. Adler JT, Mack E, Chen H. Isolated adrenal mass in patients with a history of cancer: remember pheochromocytoma. Ann Surg Oncol 2007; 14 (8): 2358-2362.

28. Rha SE, Byu JY, Yung SE, Chun HJ, Lee HG, Lee JM. Neurogenic tumors in the abdomen: tumor types and imaging characteristics. Radiographics 2003; 23 (1): 29-43.

29. Eisenhofer G, Lenders JW, Pacak K. Choice of biochemical test fo diagnosis of pheochromocytoma: validation of plasma metanephrines. Curr Hypertens Rep 2002; 4 (3): 250-255.

30. Saeger W, Fassnach M, Chita R et al. High diagnostic accuracy of adrenal core biopsy: results of the German and Austrian adrenal network multicenter trial in 220 concecutive patients. Hum Pathol 2003; 34 (2): 180-186.

31. Švajdler M, Lazúrová I, Bohus P, Palko M. Intravascular variant of diffuse large B-cell lymphoma with combined endocrine involvement. Wiener Klin Wschr 2006; 118 (13-14): 422-425.

32. Voravud N, Shin DM, Dekmezian RH, Dimery I, Lee JS, Hong WK. Implantation metastasis of carcinoma after percutaneous fine needle aspiration biopsy. Chest 1992; 102 (1): 313-315.

33. Taniai N, Egami K, Wada M,Tajiri T., Onda M. Adrenal metastasis from hepatocellular carcinoma: report of 3 cases. Hepato-Gastroenterology 1999; 46 (28): 2523-2528.

34. Carrafiello G, Lagana D, Recaldini $C$ et al. Imaging -guided percutaneous radiofrequency ablation of adrenal metastases: Preliminary results at a single institution with a single device. Cardiovascular Intervent Radiol 2008; 31 (4): 762-767.
Received January 3, 2011. Accepted January 20, 2013. 